\title{
Study on Associated Risk Factors of Hypertension at Sipaghat of Sindhupalchowk District, Nepal
}

\author{
Naresh Manandhar
}

Submitted: 22 June 2017; Accepted: 21 July 2017

\begin{abstract}
Background: Hypertension is a progressive cardiovascular syndrome arising from complex and interrelated etiologies. Males have slightly higher prevalence than female in most of countries of Southeast-Asian region.

Objective: The objective of study is to find out prevalence and the risk factors of hypertension at Sipaghat, Sindhulchowk, Nepal.

Materials and Methods: A cross-sectional study was conducted at Sipaghat of Sindhupalchowk district in May 2016 and 260 persons were selected randomly.

Results: The prevalence of hypertension was higher in male (25.4\%) than female (17.4\%). Mean age of study population was 42.08 years with standard deviation, 15.95 years. Variables namely age group, smoking, alcohol consumption and family history of hypertension were found to be significant at 5 percent level of significance. Alcohol consumption and smokers have more than two times higher chance of getting hypertension compared to alcohol non-consumer and nonsmoker with $95 \%$ confidence intervals were 1.08-4.80 and 1.21-6.10, respectively. Persons with family history of hypertension have 3.8 times more chance of getting hypertension compared to no family history of hypertension with $1.89-7.61$ of $95 \%$ confidence interval.

Conclusion: Lifestyle modification reduces blood pressure which prevents or delays the incidence of hypertension. Hypertension can be controlled and prevented by modifying the lifestyle. People should be advised to avoid modifiable risk factors of hypertension like smoking, consumption of alcohol and physical inactivity through health education programs.
\end{abstract}

Keywords: Alcohol, body mass index, family history, physical activity, smoking.

Address correspondence to the author: Department of Community Medicine, Kathmandu Medical College, Sinamangal, Kathmandu, Nepal. Ｅmail: nareshsayami@yahoo.com 


\section{INTRODUCTION}

Hypertension is a progressive cardiovascular syndrome arising from complex and interrelated etiologies. Early markers of the syndrome are often present before BP elevation (Thomas, 2009). Hypertension is defined as persistence elevation of systolic blood pressure equal to or above $140 \mathrm{~mm}$ of $\mathrm{Hg}$ or diastolic blood pressure equal to or above $90 \mathrm{~mm}$ of $\mathrm{Hg}$ (National Institute of Health, 2006). The blood pressure is considered normal if systolic blood pressure of $90-119 \mathrm{~mm}$ of $\mathrm{Hg}$ and diastolic of $70-79 \mathrm{~mm}$ of $\mathrm{Hg}$, pre-hypertension stage with systolic BP of 120-139mm of $\mathrm{Hg}$ and diastolic BP of 80-89 mm of Hg, stage I Hypertension with systolic BP of 140-159 mm of $\mathrm{Hg}$ and diastolic BP of 90-99 mm of $\mathrm{Hg}$, stage II Hypertension with systolic BP of 160- $179 \mathrm{~mm}$ of $\mathrm{Hg}$ and diastolic BP of 100-109 mm of $\mathrm{Hg}$ and Hypertensive emergency with systolic BP of $\geq 180 \mathrm{~mm}$ of $\mathrm{Hg}$ and diastolic $\mathrm{BP}$ of $\geq 110 \mathrm{~mm}$ of $\mathrm{Hg}$ (American Heart Association [AHA], 2016). About 95\% of the cases are primary hypertension where the blood pressure is high without identified cause and the remaining 5\% accounts for the secondary hypertension in which high blood pressure is related to identify cause, which include kidney disease like nephritis, diabetes mellitus, adrenal gland disease, thyroid disease, Cushing's syndrome, etc. (Manandhar, 2016). In world, hypertension affects one billion people, leading to heart attack and strokes. Hypertension kills nine million people in the world annually (WHO, 2013). Hypertension is a global health problem which affects one in three adults but remains largely hidden. Hypertension is sometimes called the "silent killer" because people who have it are often symptom free. Hypertension is a major risk factor for coronary heart disease and ischemic as well as hemorrhagic stroke. Blood pressure levels have been shown to be positively and continuously related to the risk for stroke and coronary heart disease.

Prevalence of hypertension in adults aged 25 and over was around $40 \%$ in 2008 in world and $36 \%$ male and $26.2 \%$ female in Nepal (WHO, 2011). The prevalence of hypertension was $22.7 \%$ in urban Nepal (Shrestha, 2006). Hypertension, one of the major risk factors for CVD, was estimated to be present in $27.8 \%$ of Nepalese adults aged 25 years and above (WHO, 2016). In South East-Asian region 1 out of 3 adults have high blood pressure; it is leading risk factor of death causing 1.5 million deaths each year. Males have slightly higher prevalence than female in most of countries of Southeast-Asian region. 1 in 10 individual aged between 20 and 30 years has hypertension. With age, risk increase, 5 in 10 people aged 50 and above have heart disease. It shows that hypertension increasingly affecting the working age group of people ("Result of sedentary lifestyle", 2013). 


\section{MATERIALS AND METHODS}

A cross-sectional study was conducted in Sipaghat of Sindhupalchowk district, in May 2016. Study populations are aged twenty years and above who are available at the time of data collection. The estimated sample size was 260 by using the prevalence of hypertension above 20 years was $17.7 \%$.

$$
n=\frac{4 p q}{e^{2}}
$$

where $n$ is sample size, $p$ is prevalence of hypertension $=17.7 \%, q$ is prevalence of non-hypertension $=(100-\mathrm{p})=82.3 \%$ and $e$ is allowable error $(5 \%)$.

$$
n=\frac{4 \times 17.7 \times 82.3}{5^{2}}=233
$$

Considering the $10 \%$ nonresponse rate, the sample size will be 256 and in present study samples size is approximately 260. Cluster random sampling technique was used to select household from Sipaghat and 260 individuals were interview from selected household to find out the risk factors of the hypertension. The pretested and predesigned questionnaire was used to collect information from the study population. Their diastolic and systolic blood pressures were measured in sitting position; height and weight were also measured. Body mass index was computed and classified obesity having BMI more than $25 \mathrm{~kg} / \mathrm{m}^{2}$ (WHO, 2004). Chi-square test, Odds ratio, Confidence interval were calculated for hypertension for each independent variables. The collected data were entered and analyze by using statistical package for social science (SPSS) version 20.0.

\section{RESULTS}

In the present study, female $(53.1 \%)$ were more participated than male $(46.9 \%)$. The prevalence of hypertension was higher in male (25.4\%) than female (17.4\%). Mean age of study population was 42.08 years with standard deviation of 15.95 years. The majorities (30\%) of study population were belong to the age group less than 30 years followed by $19.6 \%, 17.7 \%$ and $16.5 \%$ in the age groups 50 to 60 years, 40 to 50 years, and 30 to 40 years respectively.

The prevalence of hypertension was around $24 \%$ each in smokers and alcohol consumers. $43.2 \%$ of respondents have family history of hypertension. 
Table 1. Distribution of study population by demographic variable with hypertension.

\begin{tabular}{|c|c|c|c|c|c|}
\hline \multirow{2}{*}{ Variable } & & \multicolumn{2}{|c|}{ Hypertension } & \multirow{2}{*}{$\begin{array}{c}\mathrm{P}- \\
\text { value }\end{array}$} & \multirow{2}{*}{$\begin{array}{l}\text { Odds Ratio } \\
(95 \% \mathrm{CI})\end{array}$} \\
\hline & & Yes & No & & \\
\hline \multirow{2}{*}{ Sex } & Male & $31(25.4)$ & $91(74.6)$ & \multirow{2}{*}{0.114} & $1.61(0.88-2.94)$ \\
\hline & Female & $24(17.4)$ & $114(82.6)$ & & Ref \\
\hline \multirow{5}{*}{ Age group } & Less than 30 & $8(10.3)$ & $70(89.7)$ & 0.002 & $0.23(0.08-0.60)$ \\
\hline & $30-40$ & $9(19.6)$ & $37(80.4)$ & 0.145 & $0.48(0.18-1.28)$ \\
\hline & $40-50$ & $10(23.3)$ & $33(76.7)$ & 0.304 & $0.60(0.23-1.57)$ \\
\hline & $50-60$ & $14(27.5)$ & $37(72.5)$ & 0.538 & $0.75(0.31-1.84)$ \\
\hline & Above 60 & $14(33.3)$ & $28(66.7)$ & - & Ref. \\
\hline \multirow{5}{*}{ Education } & Illiterate & $24(23.8)$ & $77(76.2)$ & 0.281 & $2.33(0.49-10.95)$ \\
\hline & Primary & $10(20.8)$ & $38(79.2)$ & 0.414 & $1.97(0.38-10.08)$ \\
\hline & Secondary & $14(11.2)$ & $54(88.8)$ & 0.411 & $1.94(0.39-9.51)$ \\
\hline & Higher Secondary & $5(15.4)$ & $21(84.6)$ & 0.520 & $1.75(0.30-10.46)$ \\
\hline & Bachelor and above & $2(11.8)$ & $15(88.2)$ & - & Ref \\
\hline \multirow{2}{*}{ Caste } & Brahmin/ Chhetri & $2(25.0)$ & $6(75.0)$ & \multirow{2}{*}{0.780} & $1.25(0.24-6.38)$ \\
\hline & Danuwar & $53(21.0)$ & $199(79.0)$ & & Ref \\
\hline \multirow{5}{*}{ Occupation } & Farmer & $42(24.9)$ & $127(75.1)$ & 0.033 & $4.49(1.13-21.65)$ \\
\hline & Labor & $3(18.8)$ & $13(81.2)$ & 0.201 & $3.46(0.51-23.23)$ \\
\hline & Business & $3(15.0)$ & $17(85.0)$ & 0.311 & $2.64(0.40-17.44)$ \\
\hline & Housewife & $5(21.7)$ & $18(78.3)$ & 0.128 & $4.16(0.73-23.75$ \\
\hline & Others & $2(6.3)$ & $30(93.7)$ & - & Ref. \\
\hline \multirow{2}{*}{ Alcohol consumed } & Yes & $45(24.9)$ & $136(75.1)$ & \multirow{2}{*}{0.029} & $2.28(1.08-4.80)$ \\
\hline & No & $10(12.7)$ & $69(87.3)$ & & Ref \\
\hline \multirow{2}{*}{ Smoking } & Yes & $47(24.3)$ & $140(75.7)$ & \multirow{2}{*}{0.014} & $2.73(1.21-6.10)$ \\
\hline & No & $8(13.3)$ & $65(86.7)$ & & Ref \\
\hline \multirow{2}{*}{ Physical activities } & Yes & $7(14.9)$ & $40(85.1)$ & \multirow{2}{*}{0.249} & $0.60(0.25-1.43)$ \\
\hline & No & $48(22.5)$ & $165(77.5)$ & & Ref \\
\hline \multirow{2}{*}{$\begin{array}{l}\text { Family history of } \\
\text { Hypertension }\end{array}$} & Yes & $19(43.2)$ & $25(56.8)$ & \multirow{2}{*}{$<0.001$} & $3.8(1.89-7.61)$ \\
\hline & No & $36(16.7)$ & $180(83.3)$ & & Ref \\
\hline \multirow{2}{*}{$\mathrm{BMI}<25.0 \mathrm{~kg} / \mathrm{m}^{2}$} & Yes & $34(19.8)$ & $138(80.2)$ & \multirow{2}{*}{0.39} & $0.76(0.41-1.41)$ \\
\hline & No & $21(24.4)$ & $65(75.6)$ & & Ref \\
\hline
\end{tabular}

Figures in bracket are in percentage 
The hypertension was significant different with age group, alcohol consumption, smoking habit and family history of hypertension and insignificant with sex, education status, caste, occupation, physical activities and BMI. The significance of variables were also shown significant by the 95 percent confidence interval. The odds ratios of age groups were less than one with reference to age group above 60 years which mean that there was less chance of developing hypertension in younger age group compared to older age group. The odds ratios of all other significant variables were greater than one which means that there was positive association with hypertension. Higher the odds ratio there was more chances developing hypertension. The person will have more chances developing hypertension that drink alcohol, smoke cigarette and have family history of hypertension. Alcohol consumption and smokers have more than two times higher chance of getting hypertension with compared to alcohol non consumer and nonsmoker and 95\% confidence intervals were 1.08-4.80 and $1.21-6.10$ respectively. Persons with family history of hypertension have 3.8 times more chance of getting hypertension with compared to no family history of hypertension with $1.89-7.61$ of $95 \%$ confidence interval.

Table 2. Distribution of hypertensive patients by systolic and diastolic blood pressure.

\begin{tabular}{lccccc}
\hline \multirow{2}{*}{ Diastolic BP } & \multicolumn{5}{c}{ Systolic BP } \\
\cline { 2 - 5 } & $\begin{array}{c}\text { Pre- } \\
\text { Hypertension }\end{array}$ & $\begin{array}{c}\text { Stage I } \\
\text { Hypertension }\end{array}$ & $\begin{array}{c}\text { Stage II } \\
\text { Hypertension }\end{array}$ & $\begin{array}{c}\text { Hypertensive } \\
\text { Total } \\
\text { Emergency }\end{array}$ \\
\hline Normal & 1 & 0 & 1 & 0 & 2 \\
\hline Pre-hypertension & 11 & 5 & 3 & 1 & 20 \\
\hline Stage I Hypertension & 1 & 8 & 6 & 3 & 18 \\
\hline Stage II Hypertension & 0 & 6 & 3 & 2 & 5 \\
\hline Hypertensive Emergency & 0 & 1 & 15 & 7 & 55 \\
\hline Total & 13 & 20 & & 10 & 5 \\
\hline
\end{tabular}

Among the total hypertensive patients $96.36 \%$ patients were hypertensive by diastolic blood pressure and $100 \%$ by systolic blood pressure. In diastolic blood pressure, maximum patients (36.4\%) were pre-hypertensive followed by $32.7 \%, 18.8 \%$ and $9 \%$ were in stage I, stage II and hypertensive emergency respectively. In systolic blood pressure, maximum patients (36.4\%) were stage I hypertension followed by $27.3 \%, 23.6 \%$ and $12.7 \%$ were in stage II, pre-hypertension and hypertensive emergency respectively. (Table 2) 


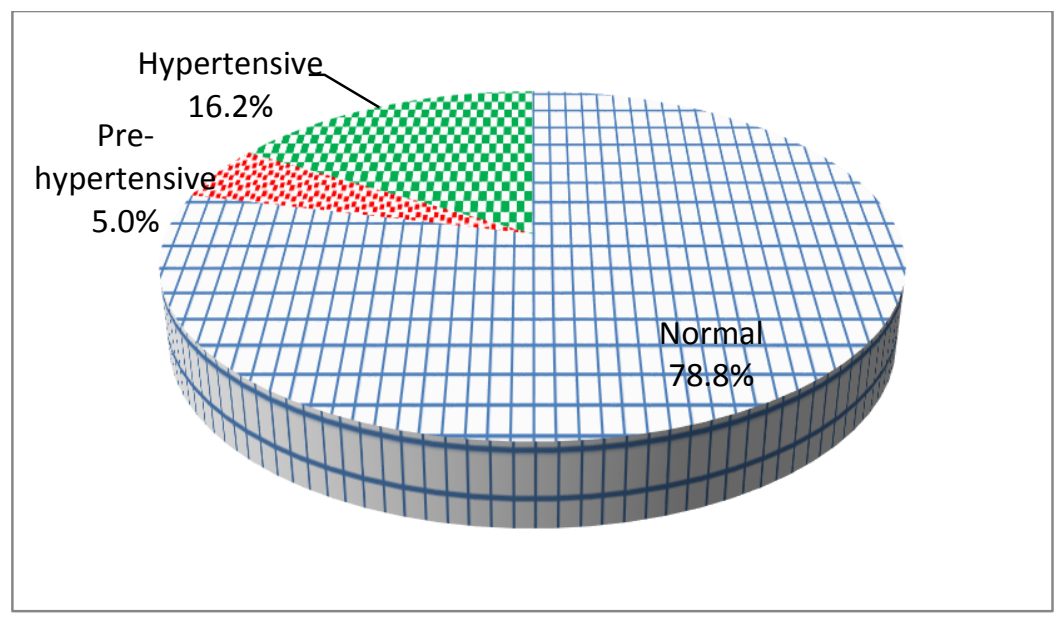

Fig. 1. Classification of respondent according to blood pressure.

\section{DISCUSSION}

Hypertension is an important public health problem because of its high prevalence and increase in risk of cardiovascular and renal disease. Many people are unaware and remain undiagnosed. Even the majority of those who are diagnosed do not get treated and change their lifestyle to control their blood pressure. In the present study, female $(53.1 \%)$ were more participated than male (46.9\%). It may be due to availability of women compared to men at home during data collection period. A study conducted in Taiwan shown that hypertension is more prevalent in female compared to male (Tsai, 2005). In the present study showed that the hypertension is more in male but the difference between male and female was not statistically significant since the p-value is more than $0.05(0.114)$.

Age group was found significant in present study which is similar to other studies of Tsai et al. (2005) and Jenel et al. (2002) where it was reported that age is strongly associated with hypertension. This increasing prevalence of hypertension is attributed to aging and behavioral risk factors such as unhealthy diet, unhealthy lifestyle, alcohol consumption, lack of physical activity, and exposure to persistent stress. In the present study showed the prevalence of hypertension was statistically significant difference as the increased in age of the persons since the p-value was 0.030. Occupation was found insignificant in the study conducted by Kumar and Sundaram (2014) in India which was similar to the present study result where religion and occupation of the study population were found insignificant. This study revealed that the BMI was insignificantly associated with hypertension since the p-value was more than 0.05. This result was inconsistent with results of Manandhar et al. (2012), Vaidya et al. (2012), Kumar (2008) and Sonmez et al. (1999). This difference may be due the location of hill area in present study and people used to work on field. 
In present study, prevalence of hypertension was found around $24 \%$ among smokers which was significant risk factor for hypertension since p-value was 0.014 and similar result was found in many other studies. The prevalence of hypertension was found around $24 \%$ each in among smokers and alcohol consumers and $43.2 \%$ of hypertensive respondents have family history of hypertension which were lower than the findings of Gautam et al. (2017) where these were $30.80 \%$ of the hypertensive were alcoholic $38.50 \%$ of smoker were Hypertensive and $57.7 \%$ had family history of hypertension.

Alcohol was found significant risk factor for hypertension in the present study. This result was similar to result of Kumar (2008), Manandhar et al. (2012), and Vaidya et al. (2012), these studies also found increase in alcohol intake aggravate the hypertension. In the present study, family history of hypertension was significantly associated with hypertension. This result was supported by the study of Kumar (2008). A study conducted in China found the variables age and smoking were significant factors for hypertension which was consistent with the present study (Zheng, Li and Cai, 2013). In many studies found physical activities as significant factor for hypertension. But in present study physical activities was insignificant for hypertension this may be due to study area which is hill and majority of respondents worked in field, which is consistent with the study done by Kumar (2008). Among the total hypertensive patients $96.36 \%$ patients were hypertensive by diastolic blood pressure and $100 \%$ by systolic blood pressure which were consistent with the finding of Manandhar and Raman (2016) (2012), where it was $94.2 \%$ patients were hypertensive by both systolic and diastolic blood pressure. Correlation coefficient between systolic BP and diastolic BP was 0.70. This result was consistent with the result of Gavish et al. (2008) and Manandhar and Raman (2016) where it were 0.74 and 0.78 , respectively.

\section{CONCLUSION}

There is evidence of hypertension due to ageing, urbanization and unhealthy lifestyles. Lifestyle modification reduces blood pressure which prevents or delays the incidence of hypertension, enhance antihypertensive drug and decrease the risk of cardiovascular disease. The hypertension leads to heart attack, stroke as well as kidney and eye damage. Early death, disability and treatment expenditure on hypertension all have effect on families and nation. Lifestyle modification has the central role in the health promotion, disease prevention and control of hypertension. Thus hypertension can be controlled and prevented by modifying the lifestyle. It helps in reducing mortality, morbidity, disabilities and socioeconomic burden due to hypertension. The present study found the significant risk factors of hypertension were age group, smoking, alcohol consumption and family history of hypertension. Health educator should advice to avoid modifiable risk factors of hypertension like smoking, alcohol consumption and change in life style. 


\section{CONFLICT OF INTEREST}

The author declared that there is no conflict of interest.

\section{ACKNOWLEDGEMENTS}

Author would like to thank all the participants for their valuable information and III MBBS students for helping in data collection. Author also thanks Dr. Sunil Kumar Joshi, Professor and head of department of Community Medicine, Kathmandu Medical College, Sinamangal for encouraging to carry out research.

\section{REFERENCES}

Gautam, A., Khan, G. A., \& Timilsina, S. (2017). Prevalence of risk factors of hypertension in Nepalese population. International Archives of Biomedical and Clinical Research, 3 (1), 4446.

Gavish, B., Ben-Dov, I. Z., \& Bursztyn, M. (2008). Linear relationship between systolic and diastolic blood pressure monitored over 24 h: Assessment and correlates. Journal of Hypertension, 26 (2), 199-209.

Jenel, Z., Pall, D., \& Katona, E. (2002). The epidemiology of hypertension and its associated risk factors in the city of Debrecen, Hungary. Public health, 116, 138-44.

Manandhar, N., \& Raman, T. P. (2016.) Risk factors of hypertension: Logistic regression analysis, SCIREA Journal of Health. 1 (1), 32-40. www.scirea.org/journal/PMH

Manandhar, K., Koju, R., Sinha, N., \& Humagain, S. (2012). Prevalence and associated risk factors of hypertension among people aged 50 years and more in Banepa Municipality, Nepal.

Kathmandu University Medical Journal, 10 (39), 35-38.

Result of sedentary lifestyle. (2009, May 27). Himalayan Times.

Kumar, S. G., \& Sundaram, N. D. (2014). Prevalence and risk factors of hypertension among bank employees in urban Puducherry, India. Int J Occup Environ Med, 5, (2), 94-100.

Kumar, S. (2008). Risk factors of hypertension: A nested case and control study in a rural community. Journal of College of Medical Sciences-Nepal, 5(1), 59-62.

Sonmez, H. M., Basak, O., \& Camci, C. (1999). The epidemiology of elevated blood pressure as an estimate for hypertension in Aydin, Turkey. J Hum Hypertens. 13, 399-404.

National Institute of Health. (2006). The seventh report of the Joint National Committee on prevention, detection, evaluation and treatment of high blood pressure. Retrieved from https://www.nhlbi.nih.gov/files/docs/guidelines/jnc7full.pdf

Giles, T. D., Materson, B. J., Cohn, J. N., \& Kostis, J. B. (2009). Definition and classification of hypertension: An update. The Journal of Clinical Hypertension, 11(11), 611-614. 
Tsai PS, Ke TL, Huang CJ (2005). Prevalence and determinants of pre-hypertension status in the Taiwanese general population. Journal of Hypertension. 2005: 23:1355-60. http://onlinelibrary.wiley.com/doi/10.1111/j.1751-7176.2009.00179.x/pdf

Shrestha, U. K., Singh, D. L., \& Bhattarai, M. D. (2006). The prevalence of hypertension and diabetes defined by fasting and 2-h plasma glucose criteria in urban Nepal. Diabetic Medicine, 23, 1130-1135.

American Heart Association. (2016). Understanding blood pressure readings. Retrieved from http://www.heart.org/HEARTORG/Conditions/HighBloodPressure/KnowYourNumbers/Un derstanding-Blood-Pressure-Readings_UCM_301764_Article.jsp\#.WYNntYSGPIU

Vaidya, A., Pathak, R., \& Pandey, M. (2012). Prevalence of hypertension in Nepalese community triples in 25 years: A repeat cross-sectional study in rural Kathmandu. Indian Heart Journal, 64 (2), 128-131.

World Health Organization. (2011). Non-communicable disease in South East Asian region: situation and response. Retrieved from http://www.searo.who.int/entity/world_health_day/en/index.html

World Health Organization. (2013). Global health observatory. Retrieved from http://www.who.int/gho/ned/risk_factor/blood_pressure_prevalace/en/

World Health Organization. (2004). Global health observatory. Retrieved from http://www.who.int/gho/ncd/risk_factors/bmi_text/en/

World Health Organization. (2016). Global health observatory. Retrieved from http://apps. who.int/gho/data/?theme=main

Zheng, Z., Li, Y., \& Cai, Y. (2013). The logistic regression analysis on risk factors of hypertension among peasants in east China \& its results validating. IJCSI International Journal of Computer Science, 10(2), 416-420.

Reference to this paper should be made as follows:

Manandhar, N. (2017). Study on associated risk factors of hypertension at Sipaghat of Sindhupalchowk district, Nepal. Nep. J. Stat., 1, 73-82. 
